American Journal of Applied Sciences 7 (10): 1420-1425, 2010

ISSN 1546-9239

(C) 2010 Science Publications

\title{
A Study of Parameters Relationship to Backcutting Phenomena During High Speed End Milling of AISI H13
}

\author{
${ }^{1}$ Erry Yulian T. Adesta, ${ }^{1}$ Afifah Mohd Ali, ${ }^{2}$ Delvis Agusman, \\ ${ }^{1}$ Muhammad Riza and ${ }^{1}$ Mohammad Yuhan Suprianto \\ ${ }^{1}$ Department of Manufacturing and Materials Engineering, Faculty of Engineering, \\ International Islamic University Malaysia, 53100 Gombak, Kuala Lumpur, Malaysia \\ ${ }^{2}$ Department of Mechanical Engineering, Faculty of Engineering, \\ Universitas Tarumanagara, Jakarta, Indonesia
}

\begin{abstract}
Problem statement: In die and mold industries, surface roughness of the dies and molds produced will determine the end product quality. Therefore, the desired finish surface was specified and the appropriate processes were selected to reach the required quality. Among many contributors to surface quality problem, backcutting is one of the factors influencing the surface roughness. Approach: The aim for current research was to study the backcutting phenomena and their effect to the surface roughness of work material, AISI H13 with hardness of $48 \mathrm{HRC}$ during high speed end milling. Machining performed on the Vertical Milling Centre (VMC) high cutting speed from 150-250 $\mathrm{m} \mathrm{min}^{-1}$, feed rate $0.05-0.15 \mathrm{~mm}$ tooth $^{-1}$ and depth of cut $0.1-0.5 \mathrm{~mm}$. The analysis and observation of the backcutting phenomena are done by using optical surface roughness machine. Results: The result shown that the pattern of surface roughness was not sufficient enough to compare between the surface with backcutting and without backcutting and the backcutting phenomena were seen mostly in combination of medium to high cutting speed and medium to high feedrate. Conclusion/Recommendations: Further research is needed with incrimination of experiments and adjustments of parameters.
\end{abstract}

Key words: Backcutting phenomena, arithmetic average, surface profile, VMC, surface roughness, optical surface, AISI H13

\section{INTRODUCTION}

In industrial machining processes, milling is a fundamental machining operation and end milling is the most common metal removal operation encountered. It is widely used in a variety of manufacturing industries including the aerospace and automotive sectors, where quality is an important factor in the production of slots, pockets, precision molds and dies. In production of molds and die, the qualities of machined parts are determined by their surface roughness and the form accuracy. Among the contribution to the surface roughness and surface texture such as machining parameters, cutting tools properties, work piece properties and cutting phenomena.

Consequences of the need for good quality in manufacturing industries and in conjuction to current world market force the manufacturing sectors to develop high quality product and process design with minimum possible cost (Sampath et al., 2009) especially which applied high speed machining, various works have been conducted by researchers. Previous studies show many efforts and contributions in the effects of cutting conditions, cutting geometry and the mechanical properties of the study piece material on dimensional precision (Lou et al., 1998; Brezocnik et al., 2004; Benardos and Vosniakos, 2003. Some other works focused on analyzing the contribution to surface imperfections of the cutting efforts originated during chip removal (Omar et al., 2007; Tang et al., 2009; Ryu et al., 2006; Schmitz et al., 2007), as well as developing theoretical and artificial intelligence models to describe dimensional imperfections in machined surface (Franco et al., 2004; 2008; Lee et al., 2001). Authors such as (Omar et al., 2007; Ryu et al., 2006); Schmitz et al., 2007; Franco et al., 2004; 2008) studied tool errors and milling machine deviations, although greater effort is required for explaining and modeling relations between these factors and the dimensional accuracy of the final part.

Corresponding Author: Erry Yulian T. Adesta, Department of Manufacturing and Materials Engineering, Faculty of Engineering, International Islamic University Malaysia, 53100 Gombak, Kuala Lumpur, Malaysia 
In spite of the previous works focused on the surface imperfections originated in milling operations, there are many factors whose influence needs more studies in order to improve the knowledge about the surface finish that can be expected on the machined part. As a continuation from the previous works, this research will focus on the study of backcutting phenomena which is one of the contributors to the surface roughness and profile during milling operation. Backcutting can be defined as the machined surface is cut once again by the trailing cutting edge (Ryu et al., 2006). Figure 1 represents the backcutting mechanism. In the milled surfaces including micro milling, backcutting, as shown in Fig. 1b, is frequently observed since finishing is conducted with light machining condition. The residual surface profile after backcutting is determined by the phase difference and the magnitude of tool deflection. The magnitude of phase difference defined in Fig. 1a is decided by the tool size and feed per tooth. Tool deflection induced by machining load reduces backcutting and affects the surface form accuracy.

Previous backcutting studies are available in the literature such as Franco et al. (2008) conducted an investigation on backcutting during face milling. Franco et al. (2004) suggested that arithmetic average roughness $(\mathrm{Ra})$ and maximum peak-to-valley height $(\mathrm{Rt})$ were noticeably decreased by backcutting surface marks.

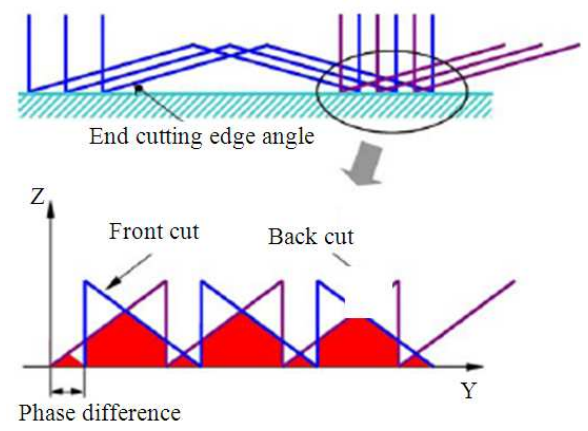

(a)

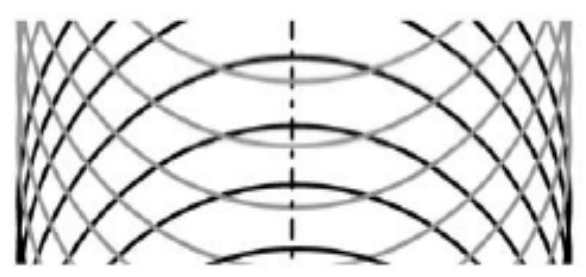

(b)

Fig. 1: The backcutting phenomena (Ryu et al., 2006) (a) backcutting mechanism (b) end milled surface with phase difference
According to the results provided by the theoretical model, Ra and Rt can be minimized by a reduction in backcutting height deviation. Other than that, Ryu et al. (2006) also studied the surface roughness and profile together with the backcutting phenomena in end milling suggested that surface roughness is better at low federate with large pick feed than that at the high federate with small pick feed. Backcutting with trailing cutting edge can improve surface roughness by proper cutting condition selection. Franco et al. (2008) in his study suggested, the surface profile of milled parts is not only affected by chip removal due to front cutting, but also by backcutting, which must be taken into account when predicting surface roughness.

Therefore, this research will study the influence of backcutting to surface roughness together with the parameters of cutting is taken into account in influencing the backcutting phenomena. The objectives needed to be fulfilled are: the influence of parameters to the backcutting phenomena as the choice of optimized cutting parameters is very important for controlling the required surface quality (Suhail et al., 2010) and the influence of backcutting to the surface roughness.

\section{MATERIALS AND METHODS}

A series of cutting tests are carried out to verify the surface generation model presented. The experiments for this research were performed on AISI H13 at Hardness of 48 Rockwell Hardness (HRC) as work material. AISI $\mathrm{H} 13$ is chosen as the work material due to it common use in die and mold industry where high speed machining is widely used nowadays. The chemical composition of the material is presented in Table 1.

Tool used is indexable tool holder Sandvick Coromill R490 with PVD coated TiAlN carbide insert. TiAlN coated carbide is applied in perspective of economical value in comparison to the tool wear rate based on previous works. The tool is properly selected as proper selection of the tool material and cutting conditions an acceptable rate of tool wear may be achieved and thus lowering the total machining cost (Ginta et al., 2009).

Table 1: Chemical composition of material

\begin{tabular}{ll}
\hline Chemical composition & Percentage \\
\hline $\mathrm{C}$ & $0.32-0.40$ \\
$\mathrm{Si}$ & $0.80-1.20$ \\
$\mathrm{P}$ & 0.011 \\
$\mathrm{~S}$ & 0.002 \\
$\mathrm{Cr}$ & $4.55-5.50$ \\
$\mathrm{Mo}$ & $1.00-1.50$ \\
$\mathrm{~V}$ & $0.80-1.20$ \\
$\mathrm{Mn}$ & Balance \\
\hline
\end{tabular}


Am. J. Applied Sci., 7 (10): 1420-1425, 2010

Table 2: Parameters and experimental result

\begin{tabular}{|c|c|c|c|c|c|}
\hline Run & $\begin{array}{l}\text { Parameter } \\
\text { cutting speed } \\
\left(\mathrm{m} \mathrm{min}^{-1}\right)\end{array}$ & $\begin{array}{l}\text { Response } \\
\text { federate } \\
\left(\mathrm{mm} \min ^{-1}\right)\end{array}$ & $\begin{array}{l}\text { Depth of } \\
\text { cut }(\mathrm{mm})\end{array}$ & $\begin{array}{l}\mathrm{Ra} \\
(\mu \mathrm{m})\end{array}$ & $\begin{array}{l}\text { Back- } \\
\text { cutting }\end{array}$ \\
\hline 1 & 150 & 0.05 & 0.10 & 0.24 & $\mathrm{x}$ \\
\hline 2 & 200 & 0.05 & 0.10 & 0.21 & $\mathrm{x}$ \\
\hline 3 & 250 & 0.05 & 0.10 & 0.28 & $\mathrm{x}$ \\
\hline 4 & 150 & 0.10 & 0.10 & 0.23 & $\mathrm{x}$ \\
\hline 5 & 200 & 0.10 & 0.10 & 0.24 & $\mathrm{x}$ \\
\hline 6 & 250 & 0.10 & 0.10 & 0.27 & $\mathrm{x}$ \\
\hline 7 & 150 & 0.15 & 0.10 & 0.26 & $\mathrm{x}$ \\
\hline 8 & 200 & 0.15 & 0.10 & 0.29 & $\mathrm{x}$ \\
\hline 9 & 250 & 0.15 & 0.10 & 0.37 & $\mathrm{x}$ \\
\hline 10 & 150 & 0.05 & 0.30 & 0.25 & $\mathrm{x}$ \\
\hline 11 & 200 & 0.05 & 0.30 & 0.33 & $\mathrm{x}$ \\
\hline 12 & 250 & 0.05 & 0.30 & 0.28 & $\mathrm{x}$ \\
\hline 13 & 150 & 0.10 & 0.30 & 0.23 & $\mathrm{x}$ \\
\hline 14 & 200 & 0.10 & 0.30 & 0.30 & I \\
\hline 15 & 250 & 0.10 & 0.30 & 0.27 & l \\
\hline 16 & 150 & 0.15 & 0.30 & 0.32 & l \\
\hline 17 & 200 & 0.15 & 0.30 & 0.47 & $\mathrm{x}$ \\
\hline 18 & 250 & 0.15 & 0.30 & 0.30 & $\mathrm{x}$ \\
\hline 19 & 150 & 0.05 & 0.50 & 0.31 & $\mathrm{x}$ \\
\hline 20 & 200 & 0.05 & 0.50 & 0.28 & $\mathrm{x}$ \\
\hline 21 & 250 & 0.05 & 0.50 & 0.39 & $\mathrm{x}$ \\
\hline 22 & 150 & 0.10 & 0.50 & 0.39 & $\mathrm{x}$ \\
\hline 23 & 200 & 0.10 & 0.50 & 0.27 & $\mathrm{x}$ \\
\hline 24 & 250 & 0.10 & 0.50 & 0.54 & I \\
\hline 25 & 150 & 0.15 & 0.50 & 0.25 & $\mathrm{x}$ \\
\hline 26 & 200 & 0.15 & 0.50 & 0.51 & I \\
\hline 27 & 250 & 0.15 & 0.50 & 0.34 & l \\
\hline
\end{tabular}

Note: /: Backcutting present; $\mathrm{x}$ : Backcutting not present

In these experiments, machining is conducted using Vertical Milling Centre (VMC) type MAZAK machine (Model Nexus 410A-II) at high cutting speed in comparison to the hardness of the material. The parameters used are; cutting speed of 150-250 $\mathrm{m} \mathrm{min}^{-1}$, feed rate $0.05-0.15 \mathrm{~mm}$ tooth $^{-1}$ and depth of cut 0.1-0.5 $\mathrm{mm}$. Parameters then are generated by using Response Surface Methodology (RSM). The parameters generated are presented in Table 2 . Surface roughness of the material after the machining are measured by using optical surface roughness measurement machine (Model: Wyto 1100).

\section{RESULTS}

In order to understand the behavior of the backcutting phenomena, the results from the observation under the optical surface roughness machine are tabulated. There are three types of results obtained. They are the 2D surface data, 3D surface display and surface profile. The example of the data collected is presented in Fig. 2 and 3. Based on these images, phenomena of backcutting are observed.

In 2D surface data from Fig. 2a, the peak and valley of the profile are indicated through contrast of color which makes it easy observation for the surface profile.

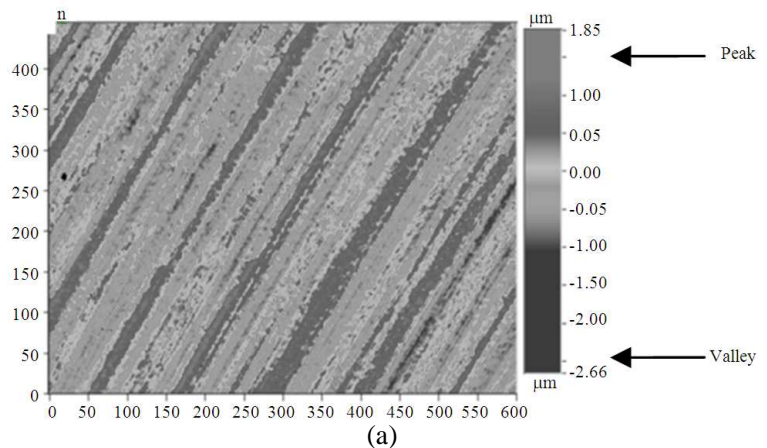

(a)

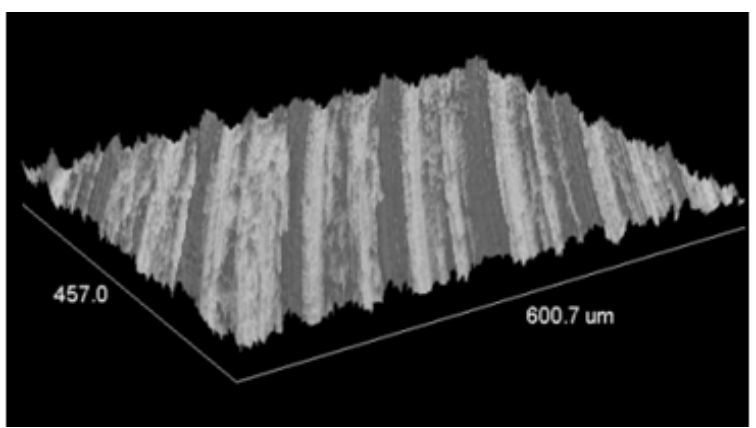

(b)

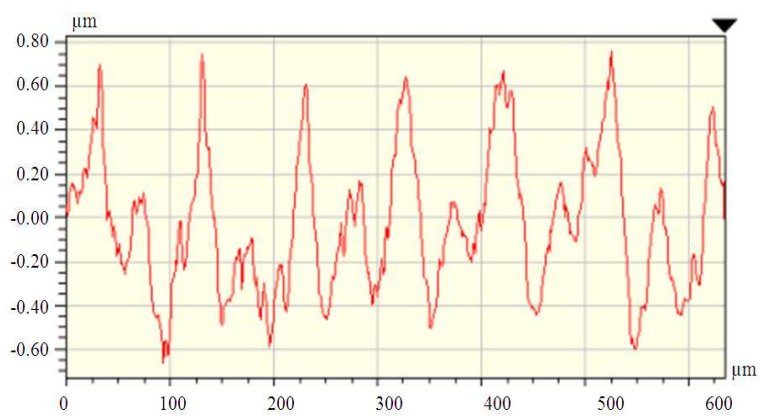

(c)

Fig. 2: Example data collected from optical surface roughness (a) 2D surface data (b) 3D surface display (c) Surface profile

The peaks are indicated by medium grey and valley in dark grey. The example of the 2D surface data can be seen in Fig. 2a. Meanwhile, through 3D surface display the peaks and valleys of the surface will be clearer as it can be seen in Fig. 2b. For surface profile, the profile of the surface is visualized clearly where the peaks and valleys are presented in term of graphs as shown in Fig. 2c. The peaks and valleys of the surface can be measured.

For clear explanation on the backcutting phenomena in these set of experiments, surface profile has been chosen for clear prove for the presence of the 1422 
backcutting. As an example of the surface with the backcutting and without backcutting, Fig. 3 is presented. In Fig. 3a, tool teeth marks on the machined surface can be seen in surface profile without backcutting phenomena and it is shown together with the predicted surface profile. The profile with waviness is the experimental profile as measured by using the optical surface roughness machine. In this figure, it can be noticed that the surface is cut only by first cut as the true profile suit the predicted profile.

Different condition is observed in Fig. $3 b$ where in this image, the first part is cut by the first edge of the insert and then cut again causing the backcutting phenomena on the surface profile. Based on this understanding, the observation of the results is done for each of surface machined for the parameters combination from RSM. RSM is a collection of mathematical and statistical techniques that are useful for the modeling and analysis of problems in which a response of interest is influenced by several variables and the objective is to optimize this response.

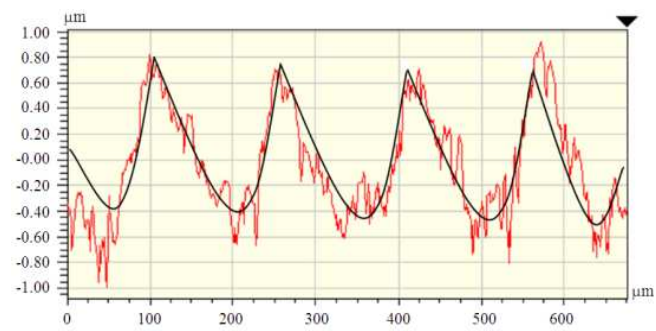

(a)

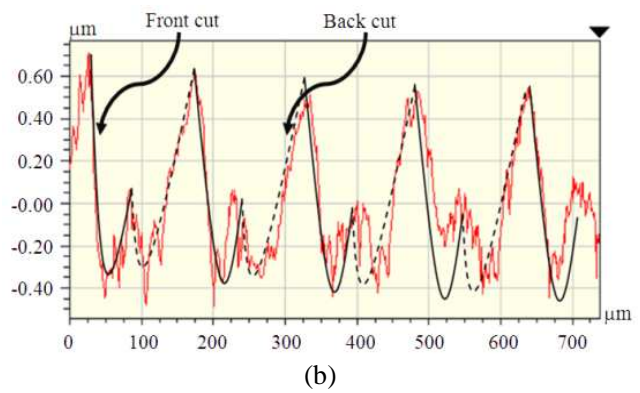

Fig. 3: Surface profile (a) without backcutting phenomena, (b) with bucketing phenomena

Table 3: Matrix of parameters Vs backcutting

\begin{tabular}{lll}
\hline Cutting speed & Federate & Backcutting \\
\hline Low & Low & $\mathrm{x}$ \\
Medium & Low & $\mathrm{x}$ \\
High & Low & $\mathrm{x}$ \\
Low & Medium & $\mathrm{x}$ \\
Medium & Medium & $/$ \\
High & Medium & $/$ \\
Low & High & $/$ \\
Medium & High & $/$ \\
High & High & $/$ \\
\hline
\end{tabular}

RSM also quantifies relationships among one or more measured responses and the vital input factors (Patwari et al., 2010). The results are tabulated in Table 2 together with the arithmetic average roughness (Ra) and maximum peak-to-valley height (Rt).

Based on the data collected also, graph of surface roughness $(\mathrm{Ra})$ versus parameters is formed. Based on these graphs, a comparison and influence of parameters to the surface roughness and backcutting is observed. It also assisted with Table 3 where matrix of parameter versus the backcutting existence is used. In this matrix, a summary of parameter in term of low, medium and high and the presence of the backcutting is tabulated to observe the behavior of the backcutting phenomena with related to the changes of the parameters.

\section{DISCUSSION}

Based on the results presented above, observations are made to fulfill the objectives of the research. Firstly, observation is made to find a pattern of behavior of the backcutting in relation to the parameters. With reference to Fig. 4 and Table 3, it is observed that the backcutting phenomena can be seen mostly in cutting speed of 200 and $250 \mathrm{~m} \mathrm{~min}^{-1}$, while for feed rate is among 0.10 and $0.15 \mathrm{~mm}$ tooth $^{-1}$ and depth of cut gives very little influence in formation of backcutting. A matrix of parameters as shown in Table 3 is formed to observe the behavior of the backcutting with related to the cutting speed and federate. A combination of cutting speed and federate will form the backcutting. The most important factor that contributes to backcutting is federate where the backcutting start to form at medium to high federate only. While for cutting speed, the backcutting appears when it is at medium and high state.

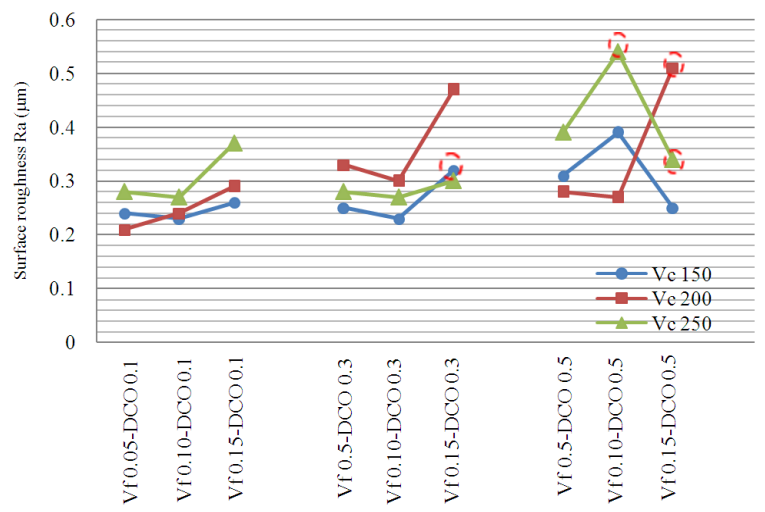

Fig. 4: Graph of surface roughness (Ra) Vs parameters Note: Vc: Cutting speed; Vf: Feedrate; DOC: Depth of cut; : Parameter with backcutting 
At low cutting speed, the backcutting will only appear when the feed rate used is at high range. This result is valid for the range of parameters as below:

$$
\begin{gathered}
0.1 \mathrm{~mm} / \mathrm{rev} \leq \text { Federate } \leq 0.15 \mathrm{~mm} / \mathrm{rev} \\
150 \mathrm{~m} / \mathrm{min} \leq \text { Cutting Speed } \leq 250 \mathrm{~m} / \mathrm{min}
\end{gathered}
$$

Besides the discussion above, an apple-to-apple comparison of $\mathrm{Ra}$ and $\mathrm{Rt}$ cannot be done as the consideration of the cutting speed, federate and depth of cut must be taken into account that influence the Ra and Rt value. Other than that, too little number of surfaces with backcutting observed which make it difficult for comparison. Therefore, further study needed in this future research in order to compare the surface profile. However, based on the study conducted by Franco et al. (2008) explained that, for these feeds, arithmetic average roughness $(\mathrm{Ra})$ and maximum peak-to-valley height (Rt) were noticeably decreased by backcutting surface marks. According to the results provided by the theoretical model, Ra and Rt can be minimized by a reduction in backcutting height deviation.

\section{CONCLUSION}

In the present study, machined part surface finish due to backcutting during flat end milling is studied. The arithmetic average roughness ( $\mathrm{Ra})$ together with the three types of surface profile images are used for observation of the backcutting phenomena. From the analysis, below conclusion is presented:

- For the range of federate $0.1-0.15 \mathrm{~mm} \mathrm{rev}^{-1}$ and cutting speed $150-250 \mathrm{~m} \mathrm{~min}^{-1}$, the backcutting phenomena can be seen mostly in medium and high range of both parameters. However, possibility of backcuting formation at low cutting speed is possible with high feedrate

- Repeated experiments needed to present apple to apple comparison on the backcutting phenomena at same parameters in order to fulfill the second objective

Based on the results, recommendation for further study can be made. Firstly, incrimination on the number of experiment on each parameter is needed in order to provide sufficient data to compare surface texture with backcutting and without backcutting phenomena. This is impotent in order to fulfill the second objective which is not fulfilled in this first phase of research. Other than that, adjustment of parameters is needed to be done. This is because the difference value of feedrate and cutting speed is quite small. Bigger difference is needed in order to get better pattern of result.

\section{ACKNOWLEDGEMENT}

The researchers would like to thank Research Management Centre (RMC), International Islamic University Malaysia for the financial support rendered to undertake this research.

\section{REFERENCES}

Benardos, P.G. and G.C. Vosniakos, 2003. Prediction of surface roughness in CNC face milling using neural networks and Taguchi's design of experiments. Int. J. Mach. Tools Manuf., 43: 833-844. DOI: 10.1016/S0890-6955(03)00059-2

Brezocnik, M., M. Kovacic and M. Ficko, 2004. Prediction of surface roughness with genetic programming. J. Mater. Process. Technol., 157-158: 28-36. DOI: 10.1016/j.jmatprotec.2004.09.004

Franco, P., M. Estrems and F. Faura, 2004. Influence of radial and axial runouts on surface roughness in face milling with round insert cutting tools. Int. J. Mach. Tools Manuf., 44: 1555-1565. DOI: 10.1016/j.ijmachtools.2004.06.007

Franco, P., M. Estrems and F. Faura, 2008. A study of backcutting surface finish from tool errors and machine tool deviations during face milling. Int. J. Mach. Tools Manuf., 48: 112-123. DOI: 10.1016/j.ijmachtools.2007.07.001

Ginta, T.L., M.A. Lajis and A.K.M. Nurul Amin, 2009. The performance of uncoated tungsten carbide insert in end milling titanium alloy Ti-6Al 4V through work piece preheating. Am. J. Eng. Applied Sci., 2: 147-153. DOI: 10.3844/ajeassp.2009.147.153

Lee, K.Y., M.C. Kang, Y.H. Jeong, D.W. Lee and J.S. Kim, 2001. Simulation of surface roughness and profile in high speed end milling. J. Mate. Process. Technol., 113: 410-415. DOI: 10.1016/S0924-0136(01)00697-5

Lou, M.S., J.C. Chen and C.M. Li, 1998. Surface roughness prediction technique for CNC endmilling. J. Ind. Technol., 15: 1-6. http://atmae.org/jit/Articles/lou1198.pdf

Patwari, M.A.U., A.K.M. Nurul Amin and W. Faris, 2010. Identification of instabilities of the chip formation and it's prediction model during end milling of medium carbon steel (S45C). Am. J. Eng. Applied Sci., 3: 193-200. DOI: 10.3844/ajeassp.2010.193.200

Omar, O.E.E.K., T. El-Wardany, E. Ng and M.A. Elbestawi, 2007. An improved cutting force and surface topography prediction model in end milling. Int. J. Mach. Tools Manuf., 47: 1263-1275. DOI: 10.1016/j.ijmachtools.2006.08.021 
Ryu, S.H., D.K. Choi and C.N. Chu, 2006. Roughness and texture generation on end milled surfaces. Int. J. Mach. Tools Manuf., 46: 404-412. DOI: 10.1016/j.ijmachtools.2005.05.010

Sampath, R.K., N. Alagumurthi and R. Ramesh, 2009. calculation of total cost, tolerance based on Taguchi's, asymmetric quality loss function approach. Am. J. Eng. Applied Sci., 2: 628-634. DOI: 10.3844/ajeassp.2009.628.634

Schmitz, T.L., J. Couey, E. Marsh, N. Mauntler and D. Hughes, 2007. Runout effects in milling: Surface finish, surface location error and stability. Int. J. Mach. Tools Manuf., 47: 841-851. DOI: 10.1016/j.ijmachtools.2006.06.014
Suhail, A.H., N. Ismail, S.V. Wong and N.A. Abdul Jalil, 2010. Optimization of cutting parameters based on surface roughness and assistance of workpiece surface temperature in turning process. Am. J. Eng. Applied Sci., 3: 102-108. DOI: 10.3844/ajeassp.2010.102.108

Tang, W.X., Q.H. Song, S.Q. Yu, S.S. Sun and B.B. Li et al., 2009. Prediction of chatter stability in high-speed finishing end milling considering multi-mode dynamics. J. Mater. Process. Technol., 209: 2585-2591.

DOI: 